\title{
Avoiding unnecessary arterial blood sampling in COPD exacerbations: a stab in the right direction
}

\author{
Andrew W Hitchings, Emma H Baker
}

Hospital admissions for exacerbations are major events in the lives of people with COPD. The prognosis for such patients is grim. Around one in seven will die within 3 months of admission, and fewer than half will still be alive at 5 years. ${ }^{1}{ }^{2}$ The symptoms they experience are frightening and unpleasant, ${ }^{3}$ their quality of life is reduced $^{4}$ and the restriction in their physical activity, which may persist for weeks after the onset of symptoms, increases the risk that they will become housebound. ${ }^{5}$ In comparison with other medical emergencies, such as myocardial infarction and stroke, progress in improving the management of COPD exacerbations has been depressingly slow. Arguably, the last major advance was the introduction of noninvasive ventilation, which took place sometime in the latter part of the last century. Against this backdrop, it is vital that, as a clinical and research community, we should tenaciously pursue all opportunities to improve the experience for these patients. In doing this, we must reflect critically on our existing practice and the pain and burdens it may present for those who endure it. In this issue of Thorax, McKeever et $a l^{6}$ do just this, by questioning the need for an investigation that many of us would consider almost sacrilegious to omit: the arterial blood gas.

Learning and refining the technique of arterial blood sampling is a rite of passage for medical students, junior doctors and increasingly other healthcare professionals. Evidence of their efforts is perhaps most conspicuous among the inpatient COPD population, where masses of haphazardly taped cotton-wool balls adorn the increasingly purpuric wrists of these unfortunate individuals. As McKeever et al have observed, the pain associated with arterial blood sampling is significantly greater than that for venous sampling, and failed attempts are more

Institute of Infection and Immunity, St George's, University of London, London, UK

Correspondence to Professor Emma H Baker, Institute of Infection and Immunity, St George's, University of London, Cranmer Terrace, London SW17 ORE, UK; ebaker@sgul.ac.uk numerous. Moreover, the risks of the procedure, including haematoma formation and distal ischaemia, are rare but potentially serious. ${ }^{7} 8$ Pain may be reduced by the prior administration of local anaesthesia $^{9}$ but, contrary to the recommendations of guideline writers, ${ }^{10}$ those on the shop floor stubbornly fail to embrace this. McKeever et al took a step back and asked the important question of whether, in fact, an arterial blood sample is always needed in the initial assessment of patients with COPD exacerbations. The validity of their question receives circumstantial support from the fact that, despite recommendations, ${ }^{11}$ audits of real-life practice consistently demonstrate that arterial blood sampling in this population is not universally applied. ${ }^{12}$ In some cases, this will simply have been an omission, but in others it may reflect a clinical judgement that the procedure, and its associated discomfort, is unjustifiable in light of the clinical information already available. Such information will invariably include non-invasive measurement of oxygen saturations $\left(\mathrm{SpO}_{2}\right)$ and, often, the results of a venous blood analysis. These are the substitute tests that McKeever et al set out to evaluate against the gold-standard arterial blood analysis.

The investigators have strengthened the evidence base informing the use of venous blood gas analysis in the context of COPD exacerbations by performing a study specifically in this population, using peripherally sampled venous blood. Their study benefits from having recruited a realistic cohort of patients with COPD exacerbations, in sufficient numbers to produce quite precise estimates of the strength of agreement between the variables of interest. They compared values obtained for $\mathrm{pH}, \mathrm{PCO}_{2}$ and $\mathrm{HCO}_{3}^{-}$from venous and arterial blood, and compared oxygen saturations from arterial blood analysis $\left(\mathrm{SaO}_{2}\right)$ with those obtained noninvasively by pulse oximetry $\left(\mathrm{SpO}_{2}\right)$. As recommended for this type of analysis, ${ }^{13}$ they described agreement using BlandAltman plots and by calculating the mean difference (ie, bias) and the 95\% limits of agreement. The latter describe the range within which $95 \%$ of differences are expected to lie. If these limits (and their confidence intervals) do not stray into differences that we would consider clinically important, then we may, for practical purposes, infer that venous and arterial measurements could be used interchangeably. The potential benefits for patients of avoiding arterial puncture, simply by analysing the venous blood that is likely to be collected anyway, are readily appreciable.

The study found that venous $\mathrm{pH}$ tends to underestimate arterial $\mathrm{pH}$ very slightly, with a mean difference of 0.03 units (ie, venous $\mathrm{pH}$ would slightly overstate the severity of arterial acidosis). The limits of agreement for $\mathrm{pH}$ measurement suggest that, in general, the arterial $\mathrm{pH}$ is expected to lie within -0.05 to +0.11 of the venous $\mathrm{pH}$ (we are not given CIs for the limits of agreement, but from those provided for the mean difference we may infer that these estimates are quite precise). Whether differences of this magnitude are clinically meaningful is, to a large extent, dependent on the observed $\mathrm{pH}$ value itself. In the initial assessment of a patient with a COPD exacerbation, the finding most likely to alter management is probably an arterial $\mathrm{pH}<7.35$. This would generally mandate hospital admission, modification of supplemental oxygen therapy and prompt consideration of ventilatory support. ${ }^{11} 14$ Thus, the level of agreement required for a venous $\mathrm{pH}$ close to this critical threshold is arguably greater than that required if the $\mathrm{pH}$ is well above this level.

The role of bicarbonate is less well defined in the context of COPD exacerbations. It serves to inform the assessment of chronic hypercapnic respiratory failure and the identification of metabolic, rather than respiratory, acidosis. The finding in this study that the arterial $\mathrm{HCO}_{3}^{-}$generally lies within about $\pm 3 \mathrm{mmol} / \mathrm{L}$ of venous $\mathrm{HCO}_{3}^{-}$is informative. Again, however, the clinical implications of this will depend on the observed value and its clinical context. As the venous $\mathrm{HCO}_{3}^{-}$ approaches the lower limit of normal, one should be increasingly concerned that an alternative process may be active, and driving a metabolic acidosis, in which case analysis of arterial blood (including for lactate concentration) would be judicious. Error in this part of the measurement range will probably be of greater significance than it would for a high bicarbonate concentration.

In contrast to the findings for $\mathrm{pH}$ and $\mathrm{HCO}_{3}^{-}$, agreement in respect of $\mathrm{PCO}_{2}$ levels and oxygen saturations was less reassuring. With the potential for venous $\mathrm{PCO}_{2}$ (ie, $\mathrm{P}_{\mathrm{v}} \mathrm{CO}_{2}$ ) to misestimate arterial 
$\mathrm{PCO}_{2}\left(\mathrm{P}_{\mathrm{a}} \mathrm{CO}_{2}\right)$ by almost $3 \mathrm{kPa}$, it is clear from this study that if accurate knowledge of $\mathrm{P}_{\mathrm{a}} \mathrm{CO}_{2}$ is necessary for clinical decision making, an arterial sample is required. Likewise, with $\mathrm{SpO}_{2}$ potentially diverging from $\mathrm{SaO}_{2}$ by more than $10 \%$, these are clearly not interchangeable measures of oxygen saturation. Interpreting the latter finding is further complicated by the fact that the reference variable, $\mathrm{SaO}_{2}$, may either be derived or measured, depending on whether the blood gas analyser has co-oximetry capabilities. Derived $\mathrm{SaO}_{2}$ values inevitably suffer from greater inaccuracy and variability due to the assumptions inherent in their calculation.

So, in light of these results, can we now omit arterial blood sampling in appropriately selected patients with a normal venous $\mathrm{pH}$, and alter the current oxygen guidelines $^{10}$ accordingly, as McKeever et al suggest? The study has made an important contribution and will undoubtedly inform the development of guidelines in this area. However, we would argue that the evidence supporting a wholesale practice change is not yet sufficient. This study must be interpreted in the context of its limitations, notably stemming from its single-centre design. There are several factors that could be particular to this centre, which may limit the generalisability of the study's findings. These include the procedural proficiency of the individuals who obtained the samples; the method used; the time taken to sample blood, decant it into a heparinised syringe and to perform blood gas analysis; and the particular analyser used. More importantly, however, the study did not seek to evaluate the effects of using the results of venous blood analysis to guide practice.
What will affect patients is not the degree to which a measured variable diverges from the gold-standard reference value, but the way in which the available clinical information-or the lack of information -affects treatment decisions and outcomes. A UK-wide randomised trial comparing the effects of treatment directed by the proposed algorithm ${ }^{6}$ against that directed by universal arterial blood gas analysis on length of stay, intensive care admissions and acceptability of care for patients with COPD hospitalised with exacerbations is now required before this approach can be universally applied.

Competing interests None declared.

Provenance and peer review Commissioned; externally peer reviewed.

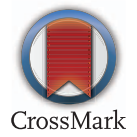

To cite Hitchings AW, Baker EH. Thorax 2016;71:208-209.

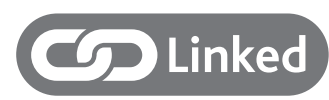

- http://dx.doi.org/10.1136/thoraxjnl-2015-207573

Thorax 2016;71:208-209.

doi:10.1136/thoraxjnl-2015-208205

\section{REFERENCES}

1 Suissa S, Dell'Aniello S, Ernst P. Long-term natural history of chronic obstructive pulmonary disease: severe exacerbations and mortality. Thorax 2012;67:957-63.

2 Buckingham RJ, Lowe D, Pursey NA, et al. Report of the national chronic obstructive pulmonary disease Audit 2008: clinical audit of COPD exacerbations admitted to acute NHS units across the UK. Royal College of Physicians of London, British Thoracic
Society and British Lung Foundation. National COPD Audit 2008 Steering Group, 2008.

3 Kessler R, Ståhl E, Vogelmeier C, et al. Patient understanding, detection, and experience of COPD exacerbations: an observational, interview-based study. Chest 2006;130:133-42.

4 Seemungal TA, Donaldson GC, Paul EA, et al. Effect of exacerbation on quality of life in patients with chronic obstructive pulmonary disease. Am J Respir Crit Care Med 1998;157:1418-22.

5 Donaldson GC, Wilkinson TM, Hurst JR, et al. Exacerbations and time spent outdoors in chronic obstructive pulmonary disease. Am I Respir Crit Care Med 2005;171:446-52.

6 McKeever TM, Hearson G, Housley G, et al. Using venous blood gas analysis in the assessment of COPD exacerbations: a prospective cohort study. Thorax 2016;71:210-5.

7 Okeson GC, Wulbrecht PH. The safety of brachial artery puncture for arterial blood sampling. Chest 1998;114:748-51.

8 Bisarya K, George S, El Sallakh S. Acute compartment syndrome of the forearm following blood gas analysis postthrombolysis for pulmonary embolism. Eplasty 2013;13:e15.

9 Lightowler JVJ, Elliott MW. Local anaesthetic infiltration prior to arterial puncture: a survey of current practice and a randomised double blind placebo controlled trial. J R Coll Physicians Lond 1997;31:645-6.

10 O'Driscoll BR, Howard LS, Davison AG, British Thoracic Society. BTS guideline for emergency oxygen use in adult patients. Thorax 2008;63 (Suppl 6): vi1-68.

11 NICE guidelines [CG101]: Chronic obstructive pulmonary disease in over 16s: diagnosis and management. National Institute for Health and Care Excellence, Jun 2010. http://www.nice.org.uk/ guidance/CG101 (accessed 29 Jan 2016).

12 National COPD Audit Programme: secondary care workstream COPD Who cares matters Clinical Audit 2014. https://www.rcplondon.ac.uk/projects/outputs/ copd-who-cares-matters-clinical-audit-2014 (accessed 18 Dec 2015).

13 Bland JM, Altman DG. Statistical methods for assessing agreement between two methods of clinical measurement. Lancet 1986;1:307-10.

14 Global strategy for the diagnosis, management and prevention of COPD. Global Initiative for Chronic Obstructive Lung Disease (GOLD); 2016. http://www. goldcopd.org/ (accessed 29 Jan 2016). 